\title{
Developing Targeted Hybrid Imaging Probes by Chelator Scaffolding
}

\author{
Dominik Summer, ${ }^{\dagger}$ Leo Grossrubatscher, ${ }^{\dagger}$ Milos Petrik, ${ }^{\ddagger}$ Tereza Michalcikova, ${ }^{\ddagger}$ Zbynek Novy, \\ Christine Rangger, ${ }^{\dagger}$ Maximilian Klingler, ${ }^{\dagger}$ Hubertus Haas, ${ }^{\S}$ Piriya Kaeopookum, ${ }^{\dagger, \|}$ \\ Elisabeth von Guggenberg, ${ }^{\dagger}$ Roland Haubner, ${ }^{\dagger}$ and Clemens Decristoforo ${ }^{*}{ }^{\dagger}$
}

\begin{abstract}
${ }^{\dagger}$ Department of Nuclear Medicine, Medical University Innsbruck, Anichstrasse 35, A-6020 Innsbruck, Austria
${ }^{\ddagger}$ Institute of Molecular and Translational Medicine, Faculty of Medicine and Dentistry, Palacky University Olomouc, Hnevotinska 5, 779 00, Olomouc, Czech Republic

${ }^{\S}$ Division of Molecular Biology/Biocenter, Medical University Innsbruck, Innrain 80-82, A-6020 Innsbruck, Austria

"Ministry of Science, Technology (MOST), Thailand Institute of Nuclear Technology (TINT), Nakhonnayok 26120, Thailand
\end{abstract}

Supporting Information

ABSTRACT: Positron emission tomography (PET) as well as optical imaging (OI) with peptide receptor targeting probes have proven their value for oncological applications but also show restrictions depending on the clinical field of interest. Therefore, the combination of both methods, particularly in a single molecule, could improve versatility in clinical routine. This proof of principle study aims to show that a chelator, Fusarinine C (FSC), can be utilized as scaffold for novel dimeric dual-modality imaging agents. Two targeting vectors (a minigastrin analogue (MG11) targeting cholecystokinin-2 receptor overexpression (CCK2R) or integrin $\alpha_{\mathrm{V}} \beta_{3}$ targeting cyclic pentapeptides (RGD)) and a near-infrared fluorophore (Sulfo-Cyanine7) were conjugated to FSC. The probes were efficiently labeled with gallium-68 and in vitro experiments including determination of $\log \mathrm{D}$, stability, protein

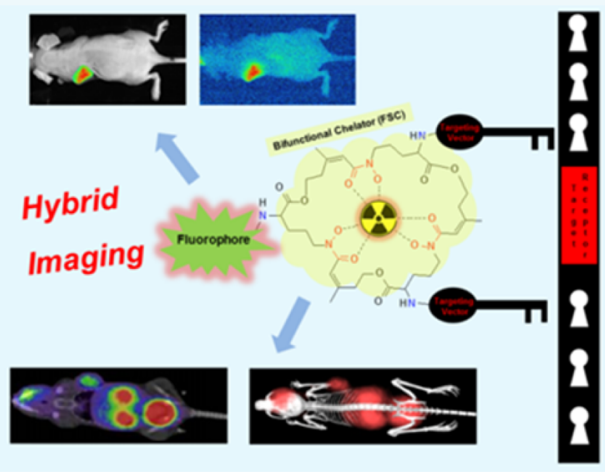
binding, cell binding, internalization, and biodistribution studies as well as in vivo micro-PET/CT and optical imaging in U-87MG $\alpha_{\mathrm{V}} \beta_{3^{-}}$and A431-CCK2R expressing tumor xenografted mice were carried out. Novel bioconjugates showed high receptor affinity and highly specific targeting properties at both receptors. Ex vivo biodistribution and micro-PET/CT imaging studies revealed specific tumor uptake accompanied by slow blood clearance and retention in nontargeted tissues (spleen, liver, and kidneys) leading to visualization of tumors at early (30 to 120 min p.i.). Excellent contrast in corresponding optical imaging studies was achieved especially at delayed time points ( 24 to $72 \mathrm{~h}$ p.i.). Our findings show the proof of principle of chelator scaffolding for hybrid imaging agents and demonstrate FSC being a suitable bifunctional chelator for this approach. Improvements to fine-tune pharmacokinetics are needed to translate this into a clinical setting.

\section{INTRODUCTION}

The overexpression of specific receptors in various tumors is utilized in modern nuclear medicine for imaging with radiolabeled peptides. A broad variety of receptors have been identified as promising targets for radiopharmaceutical development and some have been successfully implemented in clinical research and routine practice. ${ }^{1-3}$ The radionuclide gallium-68 with its availability through modern, cost-effective ${ }^{68} \mathrm{Ge} /{ }^{68} \mathrm{Ga}$ generator systems has become a radiometal of choice for targeted-PET imaging $^{4}$ and allows detection, staging, or restaging of tumor with high sensitivity. In addition to PET imaging in oncology, intraoperative tracer guidance is a very attractive approach allowing the resection of even the smallest tumor lesions while keeping the risk of surgery related nerve malfunction or unnecessary removal of nondiseased tissue as low as possible. In principle gallium- 68 labeled tracers could be used for surgical guidance via direct detection of radioactivity with hand-held gamma probes or by detection of Cerenkov luminescence generated by the emitted positrons $\left(\beta^{+}\right)$. The short half-life of gallium-68 limits this application and the use of alternative radionuclides with longer half-life such as indium111 increases the radiation burden. Gamma probes also lack the sensitivity to define the tumor margins accurately and Cerenkov luminescence is likely to vanish related to energy levels below the detectable threshold due to absorption and scattering processes. Optical imaging for intraoperative guidance via nearinfrared fluorescence is a suitable alternative. ${ }^{5}$ Under optimal conditions optical imaging can result in a spatial resolution of less than $1 \mathrm{~mm}$ generating a unique real-time visualization method to surgeons facilitating complete resection of cancerous cells. ${ }^{6,7}$ Considering the limited tissue penetration, this method is a more powerful add-on when combined with preoperative

Received: April 3, 2017

Revised: April 26, 2017

Published: May 2, 2017 


\section{Scheme 1. Synthesis of Hybrid Imaging Agents (Stereochemistry Omitted)}
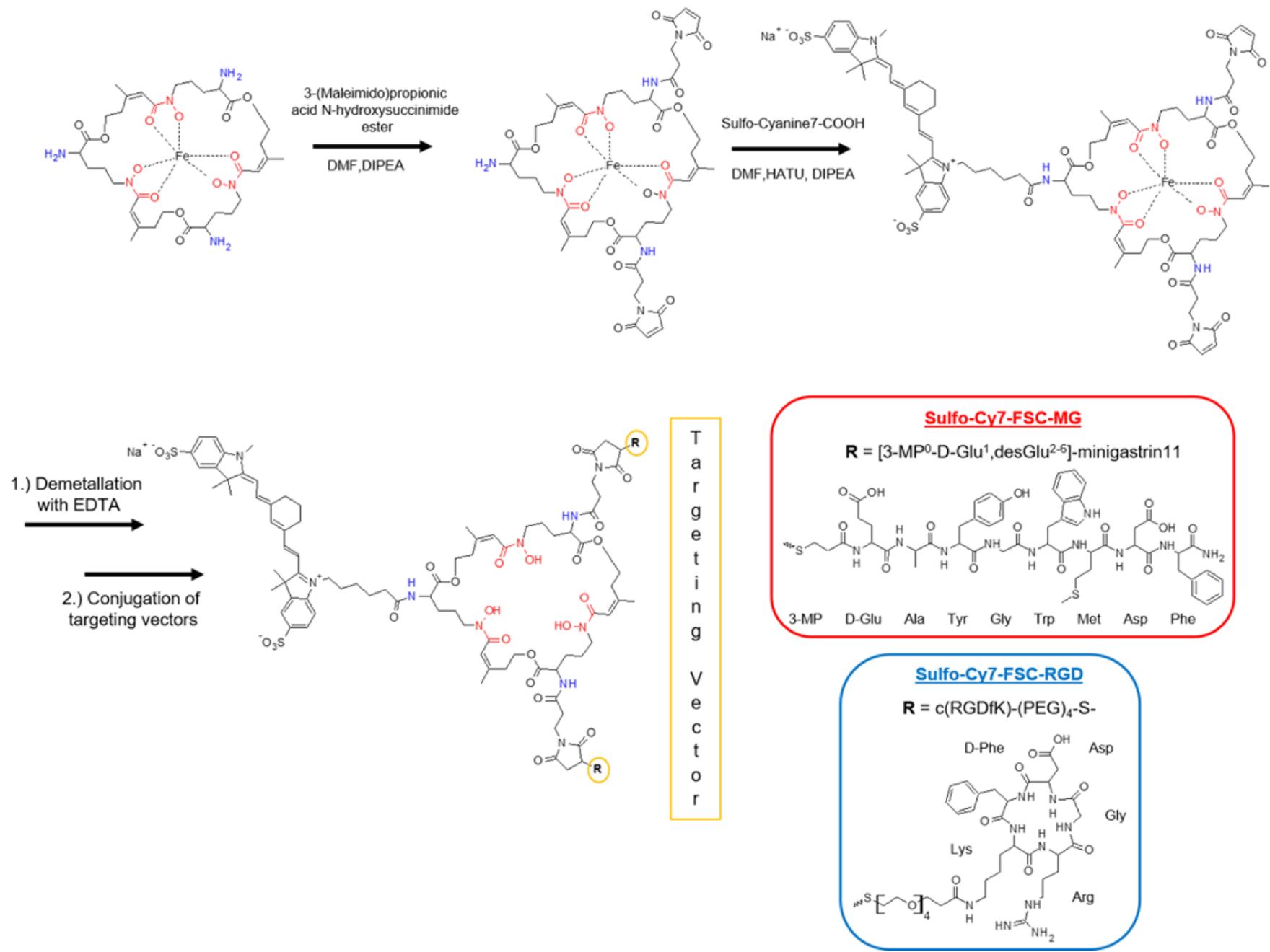

PET as a multimodality imaging technique rather than a standalone perioperative imaging method. Several preclinical studies have demonstrated the effectiveness and value of the dual-modality imaging approach. ${ }^{8,9}$ Due to the availability of novel fluorophores and targeted probes the design of single molecule based dual-modality agents has attracted great interest but also faces challenges regarding choice of fluorophore and conjugation strategy ${ }^{10-12}$ especially when strategies such as multivalency to enhance the targeting efficiency ${ }^{13}$ are applied. We have recently shown that Fusarinine C (FSC) has excellent complexing abilities concerning gallium-68 and zirconium89. ${ }^{14,15}$ Three primary amines for site-specific conjugation nominate FSC as an adaptable candidate for a dual-modality imaging approach by attaching both a targeting sequence as well as an optical imaging moiety to the chelator used for radiolabeling. Such cyclic chelator based scaffolding for hybrid imaging agents following this new conjugation strategy (Scheme 1) has to our knowledge not been described yet. In this proof of principle study we report on the synthesis and the main characteristics of two different novel divalent FSC-based hybrid imaging agents. A minigastrin analogue (MG11)targeting cholecystokinin-2 (CCK-2) receptor overexpression being involved in rare diseases like gastrointestinal stromal tumors (GIST) and medullary thyroid carcinoma (MTC) ${ }^{16}$ and the cyclic pentapeptide (RGD) - targeting integrin $\alpha_{\mathrm{V}} \beta_{3}$, a cell adhesion molecule being involved in various cancer malignancies (breast, prostate, pancreatic, ovarian, melanoma, glioblastoma, cervical $)^{17,18}$ — were chosen as model peptides for this preclinical approach.

\section{RESULTS AND DISCUSSION}

Precursor Preparation. The amino-functionalized chelator (FSC) could be extracted directly from fungal culture via an inhouse C18-cartridge method and iron was added to protect the hydroxamates and prevent any side reactions during further derivatization. Synthesis of thiolated targeting peptides for site specific maleimide conjugation was carried out using straightforward solid-phase peptide synthesis. Double-maleimide linker modified [Fe]FSC was obtained in moderate yield (>20\%, nonoptimized) out of a mixture of mono- and multiple substituted conjugates as three chemically identical primary amines cannot be derivatized individually by NHS-ester reaction strategy. Conjugation of the fluorescent dye to the remaining free amine biding site of the chelator was easily achieved by in situ activation of Sulfo-Cyanine7 carboxylic acid. Targeting vectors were conjugated after demetalation with 50 $\mathrm{mM} \mathrm{Na} \mathrm{N}_{2}$ EDTA to obtain the divalent hybrid imaging agents Sulfo-Cy7-FSC-MG and Sulfo-Cy7-FSC-RGD in good yields $(>50 \%)$. Identity of all compounds was confirmed by MALDITOF mass spectrometry. Chemical purity determined by analytical RP-HPLC (UV absorption at $\lambda=220 \mathrm{~nm}$ ) was $>95 \%$ for all intermediates and $>93 \%$ for the hybrid imaging 
agents, sufficient for this proof of principle study. From a number of candidates ${ }^{19}$ the commercially available heptamethine indocyanine based and disulfonated fluorophore-SulfoCyanine7-has been considered an appropriate choice as optical signaling moiety. It has an excitation/emission (750/ $773 \mathrm{~nm}$ ) in the near-infrared range leading to enhanced tissue penetration and high contrast in imaging, a high quantum yield, high stability, and its high water solubility matches the requirements for in vivo imaging. Additionally, the fact that structurally related indocyanine green (ICG; Cardio-Green) is the only dye being approved as injectable fluorophore for diagnostic applications in patients by the Food and Drug Administration (FDA) so far and has been used successfully in patients for more than 40 years with an excellent toxicity profile strengthened our choice. ${ }^{20}$ Similar approaches of mono- and divalent hybrid imaging agents targeting integrin $\alpha_{\mathrm{V}} \beta_{3}$ have been published ${ }^{21-24}$ while no comparable approach toward CCK2R targeting has been described so far. Still the architecture of those bioconjugates differs fundamentally from our approach as in the case of LS308 and DTPA-Lys(IRDye800)-c(KRGDf) the targeting vector as well as fluorescent dye were conjugated via a linker to the same binding site of the bifunctional chelator. In the case of DFOCypate-cyclo[RGDfK] the RGD-peptide and the chelator were attached to different binding domains of the fluorophore pointing out that FSC with multiple conjugation sites enables manifold derivatization possibilities compared to commonly used BFCs such as diethylene triamine pentoacetic acid (DTPA), 1,4,7,10-tetraazacyclododecane-1,4,7,10-tetraacetic acid (DOTA), or deferoxamine (DFO) offering only one functional group for site-specific conjugation.

Radiolabeling with Gallium-68. Both compounds could be labeled according to the detailed protocol in the Experimental Section with the radionuclide obtained from commercial available generator in $>99 \%$ radiochemical yield (RCY), with $>95 \%$ radiochemical purity (RCP) and at specific activities (SA) of $113.1 \pm 0.94 \mathrm{GBq} / \mu \mathrm{mol}(3.06 \pm 0.03 \mathrm{Ci} /$ $\mu \mathrm{mol})$ for Sulfo-Cy7-FSC-MG and $100.9 \pm 0.42 \mathrm{GBq} / \mu \mathrm{mol}$ $(2.73 \pm 0.01 \mathrm{Ci} / \mu \mathrm{mol})$ for Sulfo-Cy7-FSC-RGD $(n=3$; nonoptimized). The radiolabeled tracers were used withouth further purification for all experiments. It is highly noticeable that the formation of the radiometal chelator complex within minutes at room temperature offers mild radiolabeling conditions for sensitive biomolecules. In our case it minimized the risk to oxidize the methionine of Sulfo-Cy7-FSC-MG. This is contrary to ligands conjugated to the macrocyclic bifunctional chelator 1,4,7,10-tetraazacyclododecane-1,4,7,10-tetraacetic acid (DOTA) where heating is mandatory for radiolabeling and is highly advantageous as oxidation leads to a loss of CCK2R affinity. ${ }^{25}$

In Vitro Characterization. Partition coefficients $(\log \mathrm{D})$, protein binding, and stability assessments in fresh human serum and phosphate buffered saline (PBS; pH 7.4) of $\left[{ }^{68} \mathrm{Ga}\right]$ SulfoCy7-FSC-MG and $\left[{ }^{68} \mathrm{Ga}\right]$ Sulfo-Cy7-FSC-RGD are summarized in Table 1 . $\log \mathrm{D}$ values ranging from -1.9 to -2.3 reveal a hydrophilic character for both compounds. Binding to serum proteins was consistent over time and ranged from low for $\left[{ }^{68} \mathrm{Ga}\right]$ Sulfo-Cy7-FSC-RGD with approximately $20 \%$ to high for $\left[{ }^{68} \mathrm{Ga}\right]$ Sulfo-Cy7-FSC-MG with more than $70 \%$. Compared to a nonfluorescent divalent FSC-MG derivative $(\log \mathrm{D}=-2.5$ \pm 0.2 ; protein binding $=16.5 \pm 0.1 \%$; unpublished data) lipophilicity and protein binding of $\left[{ }^{68} \mathrm{Ga}\right]$ Sulfo-Cy7-FSC-MG increased distinctly. As the same trend could be observed
Table 1. Octanol/Water Partition Coefficient $(\log \mathrm{D})$, Protein Binding, and Stability in Human Serum (PBS as Control) of ${ }^{68}$ Ga-Labeled Hybrid Imaging Agents

\begin{tabular}{llcc} 
& & {$\left[\begin{array}{c}\left.{ }^{68} \mathrm{Ga}\right] \text { Sulfo-Cy7- } \\
\text { FSC-MG }\end{array}\right.$} & $\begin{array}{c}{\left[{ }^{68} \mathrm{Ga}\right] \text { Sulfo-Cy7- }} \\
\text { FSC-RGD }\end{array}$ \\
$\begin{array}{l}\text { Distribution } \\
\text { coefficient }\end{array}$ & $\begin{array}{c}\text { logD }(\mathrm{pH} \\
\text { Protein binding }\end{array}$ & $-1.9 \pm 0.17$ & $-2.3 \pm 0.16$ \\
& $1 \mathrm{~h}$ & $75.9 \pm 1.2$ & $20.5 \pm 0.7$ \\
& $2 \mathrm{~h}$ & $74.1 \pm 2.1$ & $20.6 \pm 0.9$ \\
Stability in PBS & $4 \mathrm{~h}$ & $73.3 \pm 1.7$ & $21.6 \pm 1.1$ \\
& $1 \mathrm{~h}$ & $95.1 \pm 0.2$ & $95.7 \pm 0.1$ \\
& $2 \mathrm{~h}$ & $94.9 \pm 0.4$ & $94.7 \pm 0.6$ \\
Stability in serum & $1 \mathrm{~h}$ & $94.4 \pm 0.1$ & $94.4 \pm 0.3$ \\
& $2 \mathrm{~h}$ & $95.5 \pm 0.6$ & $94.9 \pm 0.8$ \\
& $4 \mathrm{~h}$ & $94.5 \pm 0.5$ & $94.4 \pm 0.3$ \\
& & $93.9 \pm 0.5$ & $92.6 \pm 0.8$ \\
\hline
\end{tabular}

comparing $\left[{ }^{68} \mathrm{Ga}\right]$ Sulfo-Cy7-FSC-RGD to nonfluorescent dimeric probe DOTA-E- $[\mathrm{c}(\mathrm{RGDfK})]_{2}{ }^{26}$ or a trivalent FSC-RGD derivative ${ }^{14}$ this can be attributed to the structural properties of the fluorescent dye. Determination of stability in different media showed no significant release of gallium-68 indicating high complex stability but a slight degradation of the bioconjugates $(2-5 \%)$ was observed in the serum as well as in the PBS control. Taking into account that fluorophores are sensitive to radiolysis especially in aqueous media, ${ }^{27}$ RCP after labeling could be improved by radioprotective additives, e.g., ascorbic $\operatorname{acid}^{28}$ and this might also have positive effects regarding stability.

Cell binding studies are shown in Figure 1 and confirmed a high receptor affinity for both compounds while the difference between metal-free and metal-bound $\left(\left[{ }^{\text {nat }} \mathrm{Ga}\right]\right.$ ) bioconjugates was negligible. Sulfo-Cy7-FSC-MG showed an $\mathrm{IC}_{50}$ value of $2.81 \pm 0.66$ and $2.68 \pm 0.53 \mathrm{nM}$ in the uncomplexed and complexed form indicating improved binding affinity compared to DOTA-minigastrin $11(9.5 \pm 0.5 \mathrm{nM})$. Despite slight variances in experimental setting resulting $\mathrm{IC}_{50}$ values were comparable with a fluorescence labeled divalent minigastrin derivative (bivQ) ${ }^{29}$ and nonfluorescent divalent FSC-MG derivative $\left(0.9 \pm 0.2 \mathrm{nM}\right.$; unpublished data). An $\mathrm{IC}_{50}$ value of $1.13 \pm 0.22$ and $0.81 \pm 0.19 \mathrm{nM}$ was determined for metalfree and $\left[{ }^{\text {nat }} \mathrm{Ga}\right]$ bound Sulfo-Cy7-FSC-RGD showing enhanced affinity compared to $c(\mathrm{RGDyV})(15.19 \pm 2.86$ $\mathrm{nM}$ ). The affinity for Sulfo-Cy7-FSC-RGD is comparable to a variety of previous published nonfluorescent trivalent FSCRGD derivatives ${ }^{14,30}$ but resulted to be higher compared to integrin $\alpha_{\mathrm{V}} \beta_{3}$ targeting dimers as $\mathrm{Cy} 7-\mathrm{E}[\mathrm{c}(\mathrm{RGDyK})]_{2}{ }^{31}$ nonfluorescent DOTA-E-[c(RGDfK) $]_{2},{ }^{26}$ HYNIC/DOTA$3 \mathrm{PEG}_{4}-\mathrm{c}(\mathrm{RGDfK})_{2}{ }^{32}$ or the hybrid imaging agent DOTA(AF)SAv/biotin-PEG-RGD ${ }_{2}{ }^{24}$ Therefore, we speculate that our novel synthetic strategy can ensure unaffected peptide/ receptor interaction by preventing steric hindrance at the receptor binding site. This theory is strengthened by a recent report on a DOTA based bombesin derivative for hybrid imaging of prostate cancer where receptor affinity decreased significantly compared to nonfluorescent labeled probe when the fluorophore was conjugated to the same binding site as the targeting vector. ${ }^{9}$

Cell uptake studies using radiolabeled conjugates on A431CCK2R cells for $\left[{ }^{68} \mathrm{Ga}\right]$ Sulfo-Cy7-FSC-MG and for $\left[{ }^{68} \mathrm{Ga}\right]$ Sulfo-Cy7-FSC-RGD on M21 ( $\alpha_{\mathrm{v}} \beta_{3}$ positive) and M21-L $\left(\alpha_{\mathrm{v}} \beta_{3}\right.$ negative) cells are summarized in Figure 2 indicating highly specific receptor-mediated internalization. The internalized 

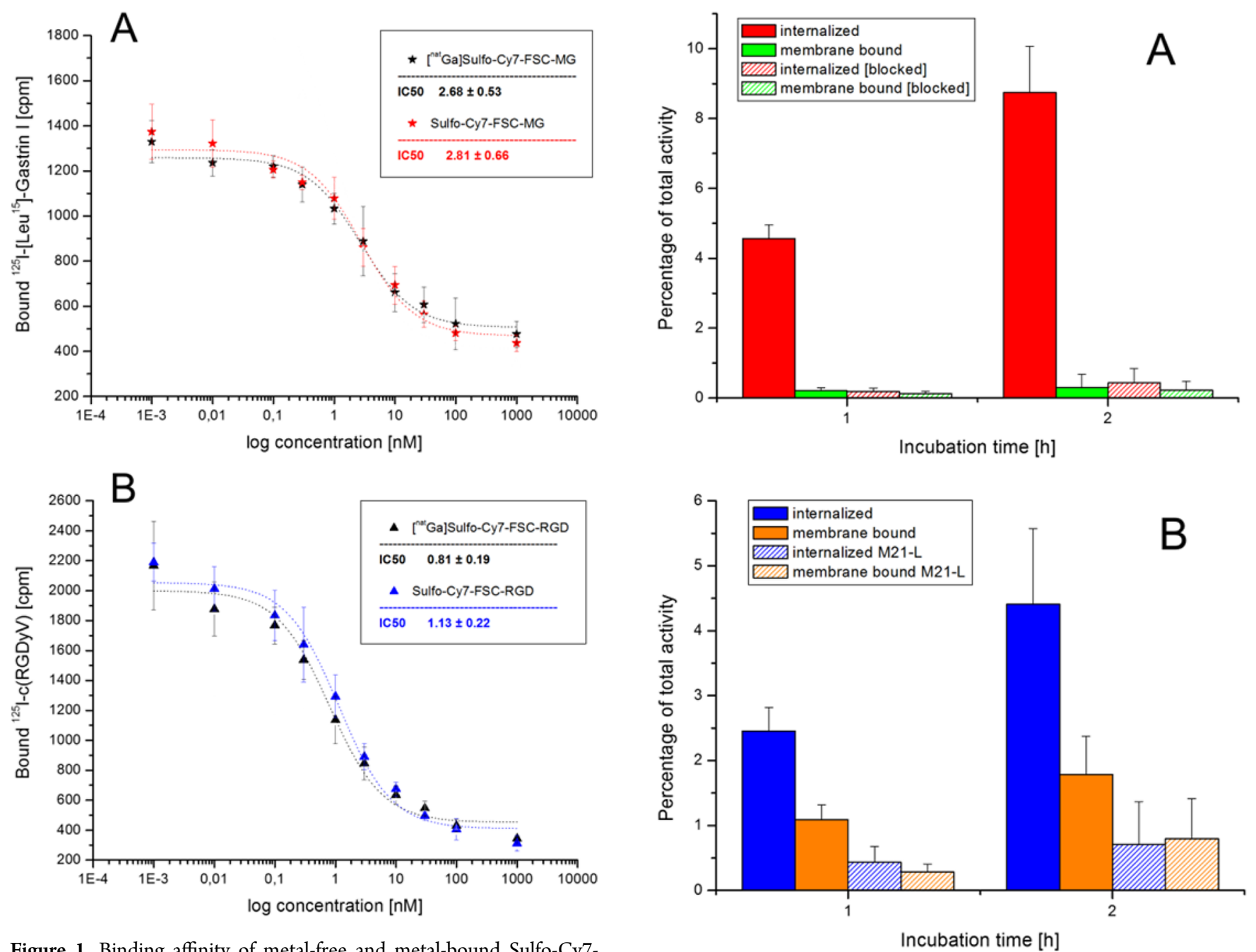

Figure 1. Binding affinity of metal-free and metal-bound Sulfo-Cy7FSC-MG on A431-CCK2 cells (A) and of Sulfo-Cy7-FSC-RGD on human melanoma M21 ( $\alpha_{\mathrm{v}} \beta_{3}$-positive) cells (B); IC I0 $_{50}$ values are expressed as mean of three individual experiments in triplicates $\pm \mathrm{SD}$.

activity for $\left[{ }^{68} \mathrm{Ga}\right]$ Sulfo-Cy7-FSC-MG resulted in $4.56 \pm 0.39 \%$ and $8.75 \pm 1.32 \%$ of total activity after 1 and $2 \mathrm{~h}$ incubation. An unspecific membrane bound amount of activity was negligibly low at both time points $(0.21 \pm 0.08 \%$ and $0.31 \pm 0.29 \%)$. Corresponding blocking studies with CCK2R receptor saturation via addition of pentagastrin in 100-fold molar excess reduced the internalized activity to $0.19 \pm 0.1 \%$ and $0.44 \pm$ $0.41 \%$ while unspecific membrane bound amount remained comparable $(0.13 \pm 0.06 \%$ and $0.25 \pm 0.23 \%)$. Cell uptake for $\left[{ }^{68} \mathrm{Ga}\right]$ Sulfo-Cy7-FSC-RGD was $2.45 \pm 0.36 \%$ and $4.41 \pm$ $1.17 \%$ and was reduced to approximately $1 / 6$ by using $\alpha_{\mathrm{v}} \beta_{3}$ negative cells $(0.43 \pm 0.25 \%$ and $0.71 \pm 0.66 \%)$ after 1 and $2 \mathrm{~h}$, respectively. The membrane bound amount of activity was 1.09 $\pm 0.23 \%$ and $1.79 \pm 0.59 \%$, respectively, on M21 cells revealing slow internalization while unspecific membrane bound activity was $0.29 \pm 0.12 \%$ and $0.80 \pm 0.62 \%$ on M21-L cells.

Fluorescence-determined cell uptake after $2 \mathrm{~h}$ incubation (Figure 3) for Sulfo-Cy7-FSC-MG resulted in $10.78 \pm 1.04 \%$ on nonblocked and $1.65 \pm 0.47 \%$ on blocked A431-CCK2R cells while Sulfo-Cy7-FSC-RGD showed $5.79 \pm 0.88 \%$ on $\alpha_{\mathrm{v}} \beta_{3}$ positive and $1.74 \pm 0.25 \%$ on $\alpha_{v} \beta_{3}$ negative cells. Somewhat higher values compared to the radioactive assay may be related to differences in experimental settings, but generally results are very comparable proving receptor specific targeting properties

Figure 2. Radio cell internalization studies after 1 and $2 \mathrm{~h}$ incubation of $\left[{ }^{68} \mathrm{Ga}\right]$ Sulfo-Cy7-FSC-MG using A431-CCK2R cells (A) and of $\left[{ }^{68} \mathrm{Ga}\right]$ Sulfo-Cy7-FSC-RGD using human melanoma M21 $\left(\alpha_{v} \beta_{3^{-}}\right.$ positive) and M21-L ( $\alpha_{\mathrm{v}} \beta_{3}$-negative) cells (B).

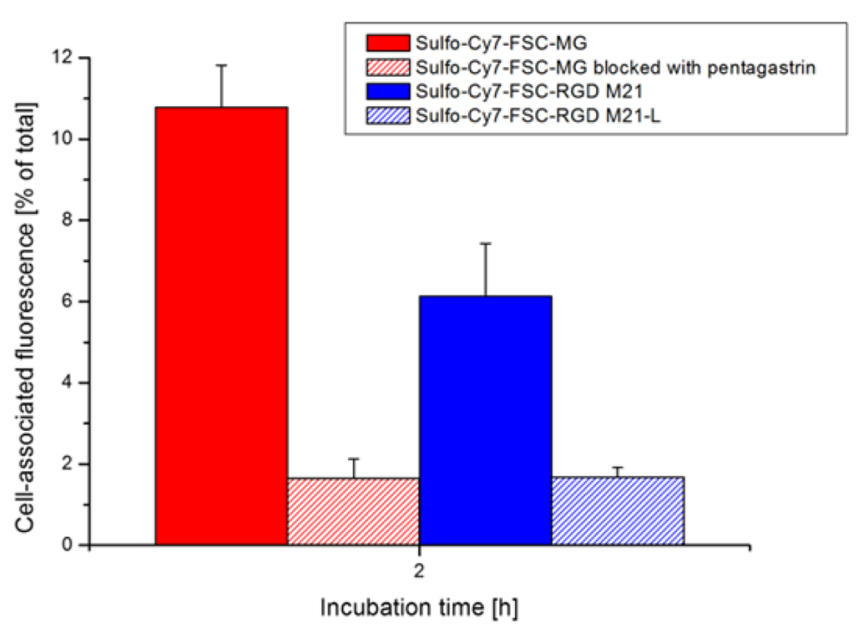

Figure 3. Fluorescence cell uptake studies after $2 \mathrm{~h}$ incubation of Sulfo-Cy7-FSC-MG using A431-CCK2R cells and of Sulfo-Cy7-FSCRGD using human melanoma M21 $\left(\alpha_{\mathrm{v}} \beta_{3}\right.$-positive $)$ and M21-L $\left(\alpha_{\mathrm{v}} \beta_{3^{-}}\right.$ negative) cells. 

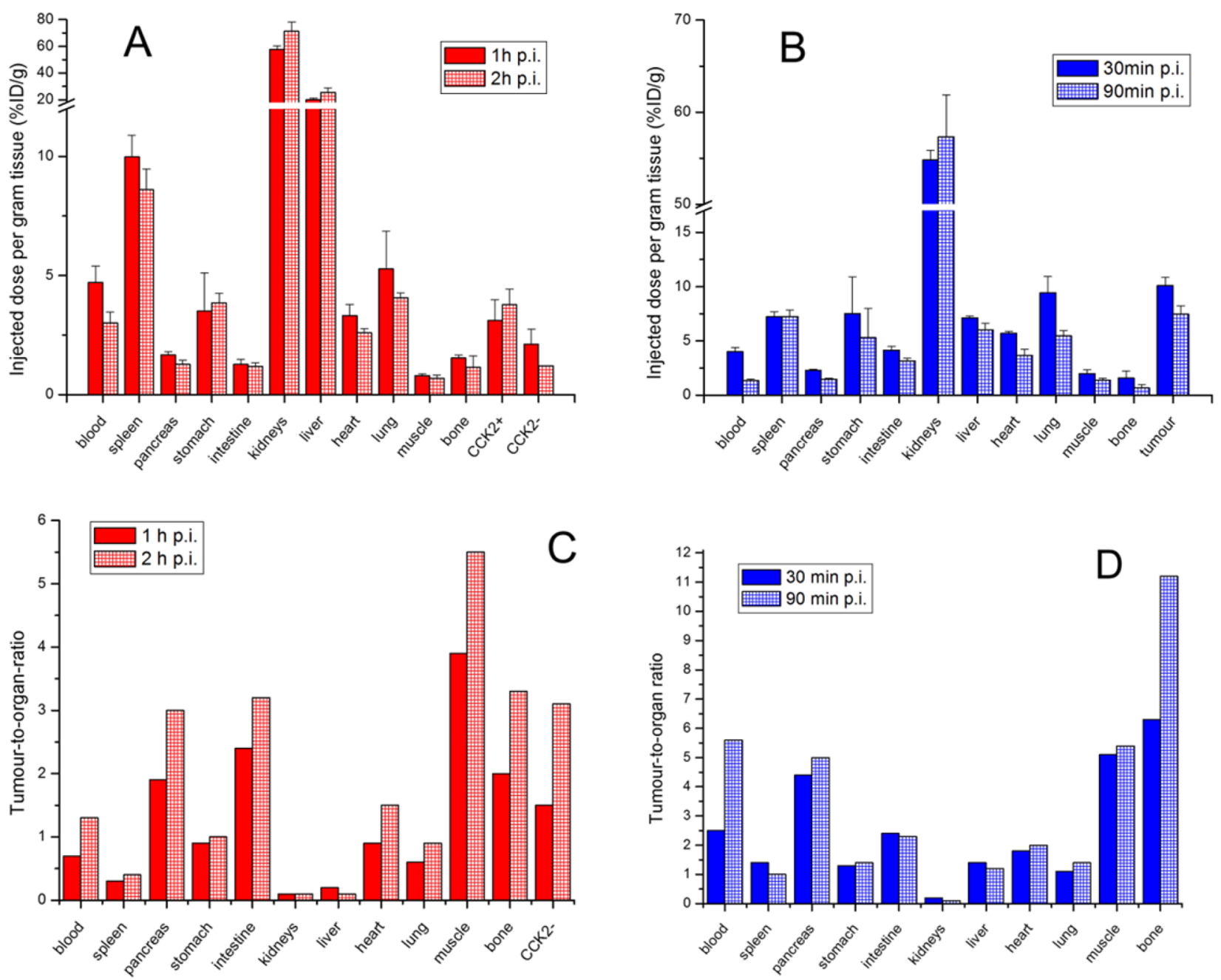

Figure 4. Ex vivo biodistribution studies in A431-CCK2R/A431-mock tumor xenografted BALB/c nude mice 1 and 2 h p.i. for $\left[{ }^{68} \mathrm{Ga}\right]$ Sulfo-Cy7FSC-MG (A) and for $\left[{ }^{68} \mathrm{Ga}\right]$ Sulfo-Cy7-FSC-RGD in U-87MG xenograft-bearing mice 30 and 90 min p.i. (B). Corresponding tumor-to-organ ratios are shown for $\left[{ }^{68} \mathrm{Ga}\right]$ Sulfo-Cy7-FSC-MG (C) and $\left[{ }^{68} \mathrm{Ga}\right]$ Sulfo-Cy7-FSC-RGD (D) (error bars omitted).

for both compounds in vitro independently whether measured via the radioactive or optical signal.

In Vivo Characterization. The results of the biodistribution studies of $\left[{ }^{68} \mathrm{Ga}\right]$ Sulfo-Cy7-FSC-MG in A431-CCK2R (receptor positive) and A431-mock (receptor negative; CCK2) xenografted BALB/c nude mice as well as of $\left[{ }^{68} \mathrm{Ga}\right]$ SulfoCy7-FSC-RGD in U-87MG $\left(\alpha_{\mathrm{v}} \beta_{3}\right.$ positive $)$ xenograft bearing mice including corresponding tumor-to-organ ratios are presented in Figure 4. $\left[{ }^{68} \mathrm{Ga}\right]$ Sulfo-Cy7-FSC-MG showed slow pharmacokinetics as the percentage of the injected dose per gram tissue $(\% \mathrm{ID} / \mathrm{g}$ ) remained comparable 1 and $2 \mathrm{~h}$ after tracer administration. The bioconjugate was highly accumulated in kidneys $(71.1 \pm 7.0 \% \mathrm{ID} / \mathrm{g} 2 \mathrm{~h} \mathrm{p.i.})$ and the resulting tumorto-kidney ratios of $<0.5$ are in agreement with mono- and divalent CCK2R targeting probes for optical imaging dQ-MG$754,{ }^{33} \mathrm{QE}$, and bivQ. ${ }^{29}$ Slow clearance from the blood indicated by a decrease from $4.7 \pm 0.7 \%$ to $3.0 \pm 0.5 \% \mathrm{ID} / \mathrm{g}$ led to a pronounced accumulation in liver tissue after $2 \mathrm{~h}(25.7 \pm 3.3 \%$ ID/g). Furthermore, the prolonged circulation of $\left[{ }^{68} \mathrm{Ga}\right]$ SulfoCy7-FSC-MG in the blood favored accumulation in nontargeted tissue especially spleen, while tumor uptake with values of $3.1 \pm 0.9 \%$ and $3.8 \pm 0.7 \% \mathrm{ID} / \mathrm{g}$ after 1 and $2 \mathrm{~h}$, respectively, showed no significant difference. Increasing CCK2R to CCK2ratios of receptor-positive (CCK2R) and -negative (CCK2-) tumors from 1.5 to 3.1 indicated target-specific tumor uptake. $\left[{ }^{68} \mathrm{Ga}\right]$ Sulfo-Cy7-FSC-RGD was highly accumulated in tumor tissue after $30 \mathrm{~min}$ p.i. $(10.1 \pm 0.8 \% \mathrm{ID} / \mathrm{g})$ and tumor washout was slow as still $7.5 \pm 0.8 \% \mathrm{ID} / \mathrm{g}$ were present in tumor tissue after $90 \mathrm{~min}$. This is in good agreement with reports of nonfluorescent radiolabeled dimeric RGD probes being evaluated on the same integrin $\alpha_{\mathrm{v}} \beta_{3}$ expressing tumor model. ${ }^{32,34}\left[{ }^{68} \mathrm{Ga}\right]$ Sulfo-Cy7-FSC-RGD was quickly cleared from the blood (decrease of $4.0 \pm 0.4 \% \mathrm{ID} / \mathrm{g}$ to $1.3 \pm 0.2 \%$ $\mathrm{ID} / \mathrm{g}$ ) moderate tracer accumulation in the liver remaining at approximately $6-7 \% \mathrm{ID} / \mathrm{g}$ and high kidney retention ranging from $54.8 \pm 1.1 \% \mathrm{ID} / \mathrm{g}$ to $57.3 \pm 4.6 \% \mathrm{ID} / \mathrm{g}$ indicates tubular reabsorption. Furthermore, slightly elevated accumulation in nontargeted organs (spleen, stomach, heart, lung) was observed possibly related to physiologic expression of integrins, ${ }^{35}$ being consistent with reports on $\left[{ }^{64} \mathrm{Cu}\right]$-DOTA-(AF)SAv/biotinPEG-RGD ${ }_{2}{ }^{24}$ and $\left[{ }^{111} \mathrm{In}\right]-\mathrm{LS} 308^{23}$ hybrid imaging agents. The high tumor/bone and tumor/muscle ratios of both bioconjugates (Figure 4C,D) confirmed the high stability found in vitro. However, some ${ }^{68} \mathrm{Ga}$ release cannot be excluded, and in particular the correlation between radionuclide release (influencing the PET signal) and in vivo stability of the FSCconjugate itself (correlating with the optical signal) warrants further investigation. 

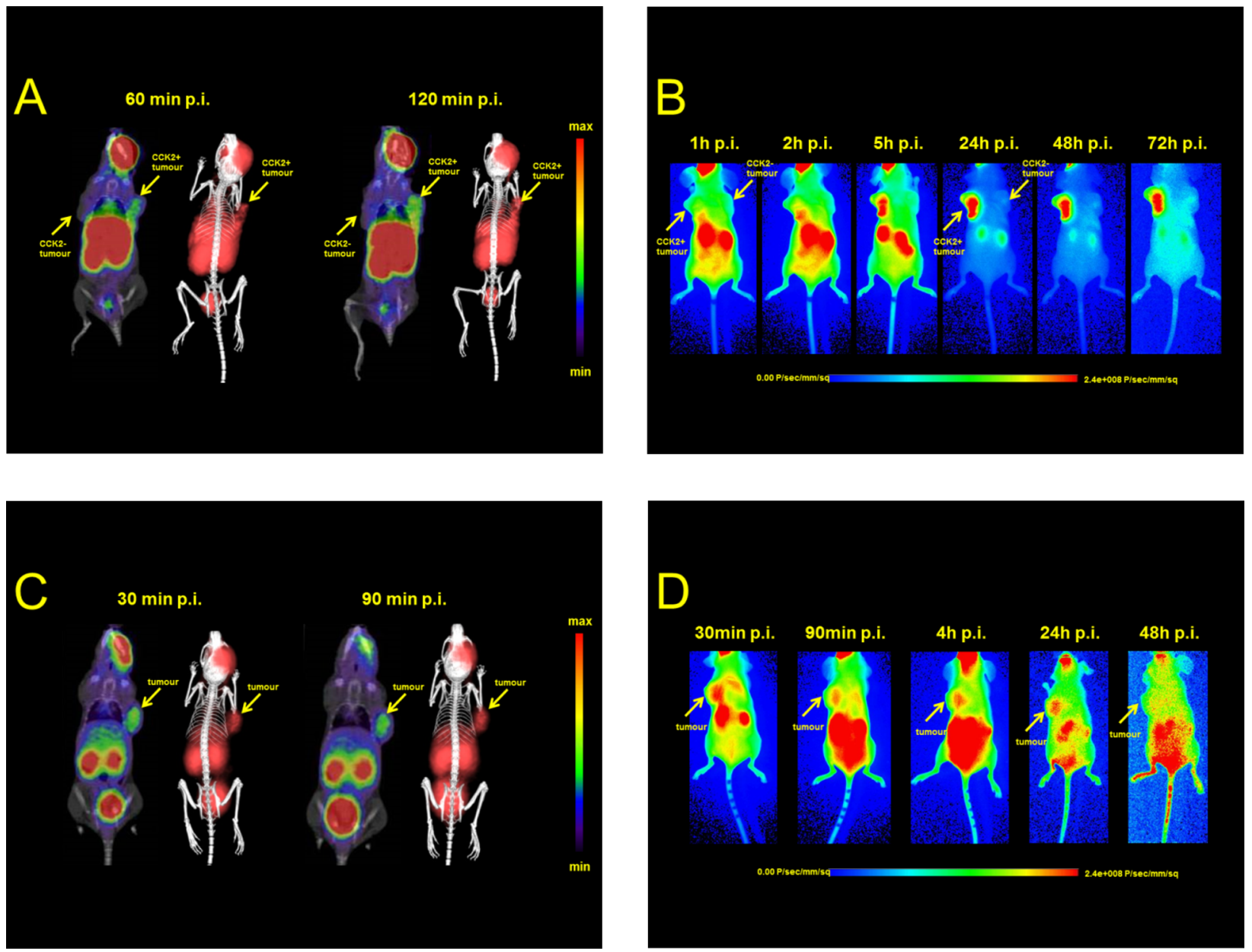

Figure 5. Dual-modality animal imaging studies: Static microPET/CT images (coronal slices) and 3D volume rendered projections of fused microPET/CT (prone position) of $\left[{ }^{68} \mathrm{Ga}\right]$ Sulfo-Cy7-FSC-MG in A431-CCK2R/A431-mock tumor xenograft-bearing BALB/c nude mice 60 and $120 \mathrm{~min}$ p.i. (A) and $\left[{ }^{68} \mathrm{Ga}\right]$ Sulfo-Cy7-FSC-RGD 30 and $90 \mathrm{~min}$ p.i. in mice bearing U-87MG tumor xenografts (C). Corresponding static nearinfrared fluorescence images (supine position) at various time intervals are shown in (B) for Sulfo-Cy7-FSC-MG and (D) for Sulfo-Cy7-FSC-RGD.

Animal imaging studies including micro-PET/CT as well as optical imaging were conducted in the same tumor mouse model as biodistribution studies and are shown in Figure 5. Static PET images of $\left[{ }^{68} \mathrm{Ga}\right]$ Sulfo-Cy7-FSC-MG confirmed the results from ex vivo biodistribution showing receptor specific uptake in CCK2R overexpressing tissue and visualized the tumor 60 and 120 min post-injection, but only moderate targetto-organ contrast was observed due to high accumulation of the tracer in liver, spleen, and kidneys not differing very much between the two time points. Optical imaging of Sulfo-Cy7FSC-MG mainly showed tracer accumulation in nontargeted tissue $1 \mathrm{~h}$ p.i., whereas tumor tissue starts to be visualized in moderate contrast $2 \mathrm{~h}$ after injection. At later time points from $5 \mathrm{~h}$ up to 3 days, respectively, imaging resulted in excellent contrast as the tracer was completely cleared from nontargeted tissue and high accumulation in tumor tissue accompanied by visualized kidneys related to renal retention was observed. Static PET images of $\left[{ }^{68} \mathrm{Ga}\right]$ Sulfo-Cy7-FSC-RGD showed highly specific receptor uptake as the tumor was visualized clearly accompanied by renal elimination and some minor unspecific binding in the gastrointestinal tract. Fluorescence imaging showed comparable results $30 \mathrm{~min}$ p.i. but higher signal for kidney and intestine $90 \mathrm{~min}$ and $4 \mathrm{~h}$ p.i., respectively, while the best contrast was achieved $24 \mathrm{~h}$ after administration. Two days after injection the ligand was completely washed out from tumor tissue being consistent with reports from the literature where different fluorescent-labeled RGD derivatives were investigated. ${ }^{24,31,36}$ Still there is room for improvement in particular reducing the lipophilic character of the fluorescent dye resulting in slow pharmacokinetics. This was also indicated as in both imaging modalities a non-negligible amount of tracer remained at the injection site showing little reabsorption. For future prospective developments these could be overcome by using fluorophores with a higher degree of sulfonation to increase hydrophilicity and prevent high protein binding ability leading to reduced hepatic clearance and improved imaging contrast. Additionally this concept could also be transferred to other cyclic chelators providing multiple coupling sites, such as TRAP $^{35}$ or a variety of DOTA/NOTA derivatives ${ }^{37}$ generating certain scientific value for further developments and clinical application regarding the hybrid imaging approach.

\section{CONCLUSION}

In this study we successfully used Fusarinine $\mathrm{C}$ as the scaffold for novel divalent hybrid imaging bioconjugates by coupling targeting vectors as well as an optical signaling moiety to the chelating core. The resulting dual-modality imaging agents $\left[{ }^{68} \mathrm{Ga}\right]$-Sulfo-Cy7-FSC-MG and $\left[{ }^{68} \mathrm{Ga}\right]-$ Sulfo-Cy7-FSC-RGD showed high radiolabeling yields, excellent stability, and receptor affinity and highly specific receptor targeting proper- 
ties. Optimization has to be carried out regarding the slow in vivo pharmacokinetics making PET studies using short-lived radionuclides difficult. The described strategy, however, offers a huge variety of possibilities to further improve and optimize in vivo properties toward targeted hybrid imaging in oncology.

\section{EXPERIMENTAL SECTION}

Instrumentation. Analytical [radio]-RP-HPLC. Reversedphase high-performance liquid chromatography analysis was carried out with a setting as follows: UltiMate 3000 RS UHPLC pump, UltiMate 3000 autosampler, UltiMate 3000 Variable Wavelength Detector (Thermo Fisher Scientific, Vienna, Austria) and a radio detector (GabiStar, Raytest; Straubenhardt, Germany). A Jupiter $4 \mu \mathrm{m}$ Proteo $90 \AA 250 \times 4.6 \mathrm{~mm}$ (Phenomenex Ltd. Aschaffenburg, Germany) column with a flow rate of $1 \mathrm{~mL} / \mathrm{min}$ and $\mathrm{UV}$ detection at $220 \mathrm{~nm}$ was used. Acetonitrile $(\mathrm{ACN}) / \mathrm{H}_{2} \mathrm{O} / 0.1 \%$ trifluoroacetic acid (TFA) was used as mobile phase with following multistep gradient: $0.0-$ $1.0 \mathrm{~min} 10 \% \mathrm{ACN}, 1.0-12.0 \mathrm{~min} 10-60 \% \mathrm{ACN}, 12.0-13.0$ min $60-80 \%$ ACN, $13.0-16.0$ min $80 \%$ ACN.

Preparative RP-HPLC. RP-HPLC-Purification was performed on a Gilson 322 Pump with a Gilson UV/vis-155 detector and a PrepFC automatic fraction collector (Gilson, Middleton, WI, USA). A Eurosil Bioselect Vertex Plus $30 \times 8$ mm $5 \mu \mathrm{m} \mathrm{C}_{18 \mathrm{~A}} 300 \AA$ A precolumn and Eurosil Bioselect Vertex Plus $300 \times 8 \mathrm{~mm} 5 \mu \mathrm{m} \mathrm{C}_{18 \mathrm{~A}} 300 \AA$ column (Knauer, Berlin, Germany) were used with a flow rate of $2 \mathrm{~mL} / \mathrm{min}$, detection at $220 \mathrm{~nm}$ and following $\mathrm{ACN} / \mathrm{H}_{2} \mathrm{O} / 0.1 \%$ TFA multistep gradients: gradient A: $0.0-1.0 \mathrm{~min} 10 \% \mathrm{ACN}, 1.0-35.0 \mathrm{~min}$ $10-60 \%$ ACN, $35.0-40.0 \min 60 \% \mathrm{ACN}, 40.0-45.0 \mathrm{~min} 80 \%$ $\mathrm{ACN}$; gradient $\mathrm{B}$ : $0.0-1.0 \mathrm{~min} 20 \% \mathrm{ACN}, 1.0-35.0 \mathrm{~min} 20-$ $60 \% \mathrm{ACN}, 35.0-40.0 \mathrm{~min} 60 \% \mathrm{ACN}, 40.0-45.0 \mathrm{~min} .80 \%$ ACN.

MALDI-TOF MS. Matrix-assisted laser desorption/ionization time-of-flight mass spectrometry was performed on a Bruker microflex benchtop MALDI-TOF MS (Bruker Daltonics, Bremen, Germany) using reflector acquisition mode, positive ion source, and 800 shots per spot. $\alpha$-Cyano-4-hydroxycinnamic acid (HCCA) was chosen as matrix and dried-droplet method for sample preparation on a micro scout target (MSP96 target ground steel BC, Bruker Daltonics). The recorded data was analyzed by Flex Analysis 2.4 software.

Radio-ITLC. Radio instant thin layer chromatography (radioITLC) analysis was performed using TLC-SG strips (Varian, Lake Forest, CA, USA) and $0.1 \mathrm{M}$ sodium citrate solution $(\mathrm{pH}$ 5 ). The strips were analyzed using a TLC scanner (Scan-RAM, LabLogistic, Sheffield, UK). Gallium-68 labeled bioconjugates remained at the start $(\mathrm{Rf}<0.1)$ while free radionuclide migrated with the solvent front $(\mathrm{Rf}>0.9)$.

$\gamma$-Counter. The radioactivity of all samples was measured in a 2480 Automatic Gamma counter Wizard2 3" (PerkinElmer, Waltham, MA, USA).

Instrumentation for animal imaging is described below.

Materials and Synthesis. General. All chemicals were purchased from commercial sources as reagent grade and used without further purification unless otherwise stated. Solid-phase peptide synthesis (SPPS) was performed according to standard Fmoc protocols and coupling efficiency was monitored by applying the Kaiser's Test. The trityl chloride polystyrene resin (TCP, 100-200 mesh) was obtained from PepChem (Reutlingen, Germany). Rink amide MBHA resin (100-200 mesh) and N-terminal 9-fluorenylmethoxycarbonyl (Fmoc) protected amino acids were purchased from Novabiochem (La
Jolla, CA, USA). Coupling reagents $O$-(7-azabenzotriazol-1-yl)1,1,3,3-tetramethyluronium-hexafluorophosphate (HATU) and 1-hydroxy-7-azabenzotriazole (HOAt) were obtained from GenScript Corporation (Piscataway, NJ, USA). All other reagents were from Sigma-Aldrich Handels $\mathrm{GmbH}$ (Vienna, Austria) and VWR International GmbH (Vienna, Austria) while Sulfo-Cyanine7 carboxylic acid was purchased from Lumiprobe GmbH (Hannover, Germany). RP-HPLC chromatograms of synthesized compounds are supplied in the Supporting Information.

Peptide Synthesis. [3-MP ${ }^{0}-D-G l u^{1}$, desGlu $\left.{ }^{2-6}\right]$-minigastrin 11 [MG11-SH]. The synthesis of the minigastrin analogue ([D$\mathrm{Glu}^{1}$, desGlu $\left.{ }^{2-6}\right]$-Ala-Tyr-Gly-Trp-Met-Asp-Phe- $\mathrm{NH}_{2}$ ) was carried out as previously described. ${ }^{38}$ Briefly, $125 \mathrm{mg}$ of Rink Amide resin $(62.5 \mu \mathrm{mol})$ was used following Fmoc protocols. For the amino acids Asp and Glu, an OtBu side chain protection was applied, whereas for Trp BOC and for Tyr, $\mathrm{tBu}$ protection groups were used and HOAT/HATU activated amino acid coupling was performed for $1 \mathrm{~h}$ at ambient temperature using 3-fold molar excess $(187.5 \mu \mathrm{mol})$. After removing the Fmoc-group from the N-terminal amino acid 3trithylsulfonylpropionic acid (Bachem, Bubendorf, Switzerland) was coupled to introduce a thiol functionality to the peptide (3$\left.\mathrm{MP}^{0}\right)$. The peptide was deprotected and cleaved from the resin with TFA/Triisopropylsilane $/ \mathrm{H}_{2} \mathrm{O}(\mathrm{v} / \mathrm{v} / \mathrm{v} ; 95 / 2.5 / 2.5)$. The crude peptide was precipitated with ice-cold diethyl ether and dissolved in $20 \% \mathrm{v} / \mathrm{v} \mathrm{ACN} / \mathrm{H}_{2} \mathrm{O}$. The peptide was purified by preparative RP-HPLC (gradient $\mathrm{B} ; t_{\mathrm{R}}=21.6 \mathrm{~min}$ ) and lyophilized. Analytical data: RP-HPLC $t_{\mathrm{R}}=12.02 \mathrm{~min}$; MALDI TOF-MS: $m / z[\mathrm{M}+\mathrm{Na}]+=1128.23,[\mathrm{M}+\mathrm{K}]+=$ 1144.24, [ $\mathrm{C}_{51} \mathrm{H}_{64} \mathrm{~N}_{10} \mathrm{O}_{14} \mathrm{~S}_{2}$; exact mass: 1105.24 (calculated)].

$c(\text { RGDFK)-(PEG) })_{4}-\mathrm{SH}[R G D-S H]$. The cyclic pentapeptide cyclo(-Arg(Pbf)-Gly-Asp(OtBu)-DPhe-Lys-) was synthesized by applying Fmoc-based solid-phase peptide synthesis for the linear precursor followed by cyclization according to Haubner and co-workers. ${ }^{39}$ Modification of the lysine side chain by $\mathrm{SAT}(\mathrm{PEG})_{4}$ coupling and deacetylation was performed following manufacturers protocol. Briefly, the peptide was dissolved in DMF and after adding $\mathrm{N}$-succidimidyl-S-acetyl(thiotetraethylene glycol) (SAT $(\mathrm{PEG})_{4}$ ) in DMSO the reaction mixture was alkalized ( $\mathrm{pH}$ 9) using DIPEA and stirred for $2 \mathrm{~h}$ at RT. The peptide was precipitated with diethyl ether and dried in vacuo. For deacetylation, the crude peptide was dissolved in PBS and 0.5 M hydroxylamine solution was added. The $\mathrm{pH}$ was adjusted to 6 and after $2 \mathrm{~h}$ reaction time the mixture was purified via preparative RP-HPLC (gradient A; $t_{\mathrm{R}}=20.4 \mathrm{~min}$ ) and dried by lyophilization. Analytical data: RP-HPLC $t_{\mathrm{R}}=9.82$ min; MALDI TOF-MS: $m / z[\mathrm{M}+\mathrm{H}]+=869.52$, $\left[\mathrm{C}_{38} \mathrm{H}_{61} \mathrm{~N}_{9} \mathrm{O}_{12} \mathrm{~S}\right.$; exact mass: 868.01 (calculated)].

Extraction and Derivatization of [Fe]Fusarinine C ([Fe]FSC). Fungal culture was carried out under iron deficiency as previously described by Schrettl and co-workers ${ }^{40}$ with slight changes regarding incubation time and different extraction methods. Briefly, $200 \mathrm{~mL}$ of Aspergillus minimal media (AMM) were inoculated with $1 \times 10^{6}$ spores $/ \mathrm{mL}$ of $\Delta$ sidG, an $A$. fumigatus mutant that lacks conversion of FSC to triacetylfusarine C, and incubated for $28 \mathrm{~h}$ at $37{ }^{\circ} \mathrm{C}$ and $200 \mathrm{rpm}$. Hereafter the biomass was filtered off and the filtrate was saturated with iron by adding $100 \mathrm{mM} \mathrm{FeCl}_{3}$ solution. The filtrate $(150 \mathrm{~mL})$ was loaded on a Reveleris flash cartridge (C18; $40 \mu \mathrm{m} ; 12 \mathrm{~g}$ and a column volume $(\mathrm{CV})$ of $18 \mathrm{~mL}$; Grace, Maryland, USA) by using a REGLO tubing pump (Type ISM795, Ismatec SA, Glattbrugg-Zürich, Switzerland) with a 
flow rate of $15 \mathrm{~mL} / \mathrm{min}$. The cartridge fixed [Fe]FSC was washed with one $\mathrm{CV}$ of water to remove unbound iron followed by elution with five $\mathrm{CV}$ of methanol. After evaporation of the organic solvent and lyophilization approximately $97 \pm 10$ $\mathrm{mg}(n=3)$ of $[\mathrm{Fe}] \mathrm{FSC}$ could be obtained as red-brown colored solid with a purity of $>90 \%$ confirmed by analytical RP$\operatorname{HPLC}\left(t_{\mathrm{R}}=6.8 \mathrm{~min}\right.$. $)$ and the product was used for further synthesis without additional purification. Analytical data: MALDI TOF-MS: $m / z[\mathrm{M}+\mathrm{H}]+=780.86,[\mathrm{M}+\mathrm{Na}]+=$ 802.87, $[\mathrm{M}+\mathrm{K}]+=818.86,\left[\mathrm{C}_{33} \mathrm{H}_{51} \mathrm{FeN}_{6} \mathrm{O}_{12}\right.$; exact mass: 779.63 (calculated)].

[Fe]FSC-(N-(3-maleinimidopropionyl) $)_{2} \quad\left([\mathrm{Fe}] \mathrm{FSC}-(\mathrm{mal})_{2}\right)$. $7.5 \mathrm{mg}[9.6 \mu \mathrm{mol}]$ [Fe]FSC were dissolved in $1 \mathrm{~mL}$ anhydrous dimethylformamide $\left(\mathrm{DMF}_{\mathrm{anh}}\right)$ and after adding 1 equiv (2.4 $\mathrm{mg}$ ) of 3-(maleimido)propionic acid (Mal) $\mathrm{N}$-hydroxysuccinimide ester in $500 \mu \mathrm{L}$ dry DMF and $4 \mu \mathrm{L} N, N$-diisopropylethylamine (DIPEA) the mixture was stirred for $2 \mathrm{~h}$ at room temperature. The reaction was monitored by analytical RPHPLC and resulted in a mixture of $[\mathrm{Fe}] \mathrm{FSC}\left(t_{\mathrm{R}}=6.8 \mathrm{~min}\right)$; $[\mathrm{Fe}] \mathrm{FSC}-\mathrm{mal}\left(t_{\mathrm{R}}=8.1 \mathrm{~min}\right) ;\left([\mathrm{Fe}] \mathrm{FSC}-(\mathrm{mal})_{2}\left(t_{\mathrm{R}}=9.5 \mathrm{~min}\right)\right.$; and $\left([\mathrm{Fe}] \mathrm{FSC}-(\mathrm{mal})_{3}\left(t_{\mathrm{R}}=11.3 \mathrm{~min}\right)\right.$. After evaporation of the organic solvent the residue was dissolved in $20 \%(\mathrm{v} / \mathrm{v}) \mathrm{ACN} /$ $\mathrm{H}_{2} \mathrm{O}$ and purified by preparative RP-HPLC (gradient A; $[\mathrm{Fe}]$ FSC-mal $\left(t_{\mathrm{R}}=14.9 \mathrm{~min}\right) ;\left([\mathrm{Fe}] \mathrm{FSC}-(\mathrm{mal})_{2}\left(t_{\mathrm{R}}=20.0\right.\right.$ $\mathrm{min}) ;\left([\mathrm{Fe}] \mathrm{FSC}-(\mathrm{mal})_{3}\left(t_{\mathrm{R}}=24.4 \mathrm{~min}\right)\right.$. After lyophilization the amount of the pure product was $2.2 \mathrm{mg}$. Analytical data: MALDI TOF-MS: $m / z[\mathrm{M}+\mathrm{H}]+=1083.34,[\mathrm{M}+\mathrm{Na}]+=$ 1105.41, $\left[\mathrm{C}_{46} \mathrm{H}_{58} \mathrm{FeN}_{8} \mathrm{O}_{18}\right.$; exact mass: 1081.88 (calculated)].

Conjugation of the Fluorophore. [Sulfo-Cyanine7-FSC$\left.(\mathrm{mal})_{2}\right]$. For the conjugation of the fluorescent dye $1 \mathrm{mg}[1.37$ $\mu \mathrm{mol}]$ of Sulfo-Cyanine7 carboxylic acid was dissolved in $1 \mathrm{~mL}$ $\mathrm{DMF}_{\text {anh. }}$ and after addition of 1 equiv [0.52 mg] HATU the mixture was left for $10 \mathrm{~min}$ at room temperature to activate the carboxylic acid. Subsequently 1.1 equiv of $[\mathrm{Fe}] \mathrm{FSC}-(\mathrm{mal})_{2}$ and DIPEA were added and the reaction was stirred for further 30 min. After analytical RP-HPLC confirmed the reaction to be finished the organic solvent was removed under vacuo and 2 $\mathrm{mL}$ of $50 \mathrm{mM}$ ethylenediaminetetraacetic acid disodium salt $\left(\mathrm{Na}_{2} \mathrm{EDTA}\right)$ solution were poured onto the crude product and stirring was continued overnight for iron removal $\left(+\mathrm{Fe}^{3+} t_{\mathrm{R}}=\right.$ $\left.11.3 \mathrm{~min}),-\mathrm{Fe}^{3+} t_{\mathrm{R}}=11.5 \mathrm{~min}\right)$. Finally the product was isolated via preparative RP-HPLC (gradient A: $t_{\mathrm{R}}=30.1 \mathrm{~min}$ ) and freeze-dried. Yield was $1.27 \mathrm{mg}$ [0.73 $\mu \mathrm{mol}$; 53\%] as dark green colored solid. Analytical data: MALDI TOF-MS: $m / z$ [M $+\mathrm{H}]+=1724.37,[\mathrm{M}+\mathrm{Na}]+=1747.54,\left[\mathrm{C}_{84} \mathrm{H}_{107} \mathrm{~N}_{10} \mathrm{O}_{25} \mathrm{~S}_{2}\right.$; exact mass: 1720.93 (calculated)].

Conjugation of the Targeting Vectors. Sulfo-Cyanine7FSC-(mal-peptide) ${ }_{2}$. For site specific peptide conjugation SulfoCyanine7-FSC- $(\mathrm{mal})_{2}$ was dissolved in $0.5 \mathrm{~mL}$ phosphate buffered saline (PBS) and either RGD-SH or MG11-SH were dissolved in PBS and added in excess. After $30 \mathrm{~min}$ at room temperature the reaction solutions were directly purified by preparative RP-HPLC (gradient A, Sulfo-Cy7-FSC-MG $t_{\mathrm{R}}=$ $35.6 \mathrm{~min}$ and Sulfo-Cy7-FSC-RGD $t_{\mathrm{R}}=32.6 \mathrm{~min}$ ) and the hybrid imaging ligands were lyophilized giving dark green colored solids.

Sulfo-Cyanine7-FSC-(mal-MG11) ${ }_{2}$ [=Sulfo-Cy7-FSC-MG $]$ $1.30 \mathrm{mg}[0.25 \mu \mathrm{mol} ; 55 \%]$; analytical data: RP-HPLC $t_{\mathrm{R}}=$ $12.6 \mathrm{~min}$; MALDI TOF-MS: $m / z[\mathrm{M}+\mathrm{H}]+=3932.09,[\mathrm{M}+$ $\mathrm{Na}]+=3954.98 \quad\left[\mathrm{C}_{186} \mathrm{H}_{235} \mathrm{~N}_{30} \mathrm{O}_{53} \mathrm{~S}_{6}\right.$; exact mass: 3931.42 (calculated)].

Sulfo-Cyanine7-FSC-(mal-c(RGDfK)- $\left.\left(\mathrm{PEG}_{4}\right)\right)_{2} \quad[=$ SulfoCy7-FSC-RGD] $0.5 \mathrm{mg}[0.15 \mu \mathrm{mol} ; 58 \%]$; analytical data:
RP-HPLC $t_{\mathrm{R}}=10.8 \mathrm{~min}$; MALDI TOF-MS: $m / z[\mathrm{M}+\mathrm{H}]+=$ 3457.01, $[\mathrm{M}+\mathrm{Na}]+=3480.18, \quad\left[\mathrm{C}_{160} \mathrm{H}_{229} \mathrm{~N}_{28} \mathrm{O}_{49} \mathrm{~S}_{4}\right.$; exact mass: 3456.95 (calculated)].

Radiochemistry. For radiolabeling ${ }^{68} \mathrm{Ga}$-chloride was obtained by eluting a commercial ${ }^{68} \mathrm{Ge} /{ }^{68} \mathrm{Ga}$-generator (IGG100, Eckert \& Ziegler Isotope products, Berlin, Germany; nominal activity of $1850 \mathrm{MBq}$ ) with $0.1 \mathrm{M}$ hydrochloric acid ( $\mathrm{HCl}$, Rotem Industries, Israel). Fractionated elution method was used to increase the activity to volume ratio to its maximum. Peptides (10 $\mu \mathrm{g} ; 2.5-2.9 \mathrm{nmol})$ were incubated with $100-200 \mu$ L eluate $(15-35 \mathrm{MBq})$ and $\mathrm{pH}$ was adjusted to 4.5 by adding $20-40 \mu \mathrm{L} 1.14 \mathrm{M}$ sodium acetate solution. After 5 to $10 \mathrm{~min}$ incubation at ambient temperature samples were analyzed by radio-RP-HPLC as well as radio-ITLC. Corresponding chromatograms are shown in the Supporting Information.

Distribution Coefficient ( $\log D)$, Serum Stability, and Protein Binding. $\left[{ }^{68} \mathrm{Ga}\right]$ Sulfo-Cy7-FSC-MG and $\left[{ }^{68} \mathrm{Ga}\right]$ SulfoCy7-FSC-RGD (6 MBq) were diluted with phosphate buffered saline to a concentration of $1 \mu \mathrm{M}$. Subsequently $50 \mu \mathrm{L}$ of this solution was added to six Eppendorf tubes containing $450 \mu \mathrm{L}$ PBS and $500 \mu \mathrm{L}$ octanol. The mixture was vortexed (1400 $\mathrm{rpm}$ ) at RT for $15 \mathrm{~min}$ using a MS 3 basic vortexer (IKA, Staufen, Germany) followed by centrifugation for $2 \mathrm{~min}$ at 4500 rpm. Aliquots of $100 \mu \mathrm{L}$ of both phases were transferred to plastic vials, measured in the $\gamma$-counter and $\log \mathrm{D}$ values were calculated. For stability testing, radiolabeled tracers were diluted with $450 \mu \mathrm{L}$ fresh human serum and $450 \mu \mathrm{L}$ PBS as control to a concentration of $2 \mu \mathrm{M}$ followed by incubation at $37{ }^{\circ} \mathrm{C}$. After 1,2 , and $4 \mathrm{~h}(n=3) 50 \mu \mathrm{L}$ aliquots were precipitated with acetonitrile $(1: 1)$ and centrifuged for $2 \mathrm{~min}$ at $14 \times 10^{3} \mathrm{rpm}$. The supernatant was analyzed by radio-RPHPLC to evaluate for decomposition and corresponding chromatograms are shown in Supporting Information. For protein binding measurement aliquots were analyzed by size exclusion chromatography using MicroSpin G-50 Columns (Sephadex G-50, GE Healthcare, Vienna, Austria) in triplicates. First, the columns were centrifuged at $750 \mathrm{rcf}$ for $1 \mathrm{~min}$ to remove the storage buffer. After adding $25 \mu \mathrm{L}$ of incubation solution columns were centrifuged again for 2 min with 2000 rcf. Column and eluate were measured in the $\gamma$-counter and percentages of nonprotein bound radiolabeled peptide (column) and protein bound radiotracer (eluate) were calculated.

Tumor Cell Lines and Cell Culture. Culture media and additives were purchased from Gibco, Invitrogen Corporation, Paisley, UK. All cell lines were grown at $37{ }^{\circ} \mathrm{C}$ in a humidified atmosphere of $95 \%$ air $/ 5 \%$ carbon dioxide and split approximately every $72 \mathrm{~h}$. The human squamous carcinoma cell line A431 transfected with the human CCK-2 receptor $(\mathrm{A} 431-\mathrm{CCK} 2 \mathrm{R})^{41}$ and transfected with the empty vector alone (A431-mock) was a kind gift from L. Aloj (Nuclear Medicine Unit, Istituto Nazionale per lo Studio e la Cura dei Tumori "Fondazione Giovanni Pascale" - IRCCS, Naples, Italy) and was seeded in tissue culture flasks (Cellstar; Greiner Bio-One, Kremsmuenster, Austria) using Dulbecco's Modified Eagle's Medium (DMEM) supplemented with $10 \% \mathrm{v} / \mathrm{v}$ fetal bovine serum (FBS) and $1 \% \mathrm{v} / \mathrm{v}$ penicillin-streptomycin-glutamin (PSG) solution. Human melanoma M21 and M21-L (with and without integrin $\alpha_{\mathrm{V}} \beta_{3}$ expression) cells were a kind gift from D. A. Cheresh (Departments of Immunology and Vascular Biology, The Scripps Research Institute, La Jolla, CA, USA) and were grown in tissue culture flasks using DMEM medium 
while M21-L cells were maintained in germ count dishes (Greiner Bio-One) in RPMI 1640 cell culture medium both media containing $10 \% \mathrm{v} / \mathrm{v}$ FBS and $1 \% \mathrm{v} / \mathrm{v}$ PSG as additive. Human glioblastoma U-87MG cell line as alternative model for integrin $\alpha_{\mathrm{V}} \beta_{3}$ expression was purchased from American Type Culture Collection (ATCC, Manassas, Virginia, USA) and was cultured in tissue culture flasks using Eagle's Minimum Essential Medium (EMEM) containing 10\% v/v FBS as supplement.

In Vitro Studies. CCK-2 Receptor Internalization Assay. To determine the receptor-mediated radioligand uptake A431CCK2R cells were seeded into 12 -well plates (Nunc, Thermo Scientific) with a density of $2 \times 10^{6}$ cells per well and left to grow overnight at $37^{\circ} \mathrm{C}$. At the day of the experiment each well was washed twice with fresh internalization medium (DMEM containing $1 \%$ fetal bovine serum) followed by the adjustment to a final volume of $1.2 \mathrm{~mL}$ with media. After dividing the plate into an unblocked and blocked compartment (6 wells each) $150 \mu \mathrm{L}$ PBS $/ 0.5 \%$ bovine serum albumin (BSA) solution or $150 \mu \mathrm{L}$ blocking solution (100-fold molar excess of pentagastrin in PBS/0.5\% BSA solution) were added and left for $10 \mathrm{~min}$ at room temperature. Hereafter, $150 \mu \mathrm{L}$ of the radiolabeled peptide ( $1 \mathrm{nM}\left[{ }^{68} \mathrm{Ga}\right]$ Sulfo-Cy7-FSC-MG in PBS/ $0.5 \%$ BSA approximately $3 \times 10^{4} \mathrm{cpm}$ ) was added to each well followed by incubation at $37{ }^{\circ} \mathrm{C}$ for 1 and $2 \mathrm{~h}$, respectively. After removal of the supernatant each well was washed two times with $1 \mathrm{~mL}$ ice-cold internalization medium and supernatants were collected in plastic vials (wash fraction). For determination of the membrane bound radiotracer cells were incubated twice with $1 \mathrm{~mL}$ ice-cold $0.05 \mathrm{M}$ glycine-buffer ( $\mathrm{pH} 2.8$ ) for 5 min collecting the supernatants. Finally, internalized fraction was obtained by lysing the cells with $1 \mathrm{~mL}$ of $2 \mathrm{M}$ sodium hydroxide solution $(\mathrm{NaOH})$ two times and collecting the samples. To determine the amount of radiotracer of each fraction all samples were taken for $\gamma$-counter measurement against standard solution, i.e., $150 \mu \mathrm{L}$ radiotracer.

M21/M21-L Internalization Assay. Integrin $\alpha_{\mathrm{v}} \beta_{3}$ positive (M21) and $\alpha_{\mathrm{v}} \beta_{3}$ negative (M21-L) cells were diluted with incubation medium, i.e., corresponding growth medium containing $1 \%$ glutamine $(\mathrm{m} / \mathrm{v}), 1 \% \mathrm{BSA}(\mathrm{m} / \mathrm{v}), \mathrm{CaCl}_{2}(1$ $\mathrm{mM}), \mathrm{MgCl}_{2}(1 \mathrm{mM})$, and $\mathrm{MnCl}_{2}(10 \mathrm{mM})$ to a concentration of $2.0 \times 10^{6} \mathrm{cells} / \mathrm{ml}$. Aliquots of one milliliter were transferred to Eppendorf tubes and six technical replicates for each cell line were incubated for $1 \mathrm{~h}$ at $37^{\circ} \mathrm{C}$. Subsequently $50 \mu \mathrm{L}$ of the radiolabeled ligand (1.2 $\mathrm{nM}\left[{ }^{68} \mathrm{Ga}\right]$ Sulfo-Cy7-FSC-RGD in PBS/0.5\% BSA, approximately $2 \times 10^{4} \mathrm{cpm}$ ) were added and incubated at $37{ }^{\circ} \mathrm{C}$ for further 60 and $120 \mathrm{~min}$, respectively. After incubation the tubes were centrifuged $(2 \mathrm{~min}, 5000 \mathrm{rpm}$; Eppendorf Centrifuge 5424, Hamburg, Germany) and the supernatant was removed and collected. Hereafter the cells were washed twice with $1 \mathrm{~mL}$ ice-cold washing buffer $(10 \mathrm{mM}$ TRIS-buffered saline, $\mathrm{pH}$ 7.3) and the fractions were combined with the supernatant (wash fraction). To determine the membrane bound tracer amount cells were washed two times with $1 \mathrm{~mL}$ acetate buffer $\left(20 \mathrm{mM}, \mathrm{pH} 4.5,10 \mathrm{~min}\right.$ at $\left.37^{\circ} \mathrm{C}\right)$ and the supernatant was collected. The residual cells were lysed by adding $1 \mathrm{~mL}$ of $2 \mathrm{M} \mathrm{NaOH}$ twice and collected in plastic vials (internalized fraction). The activity of all collected vials was measured in the $\gamma$-counter and compared to standard solution (50 $\mu \mathrm{L}$ radiotracer).

Fluorescence Measured Cell Specificity. Fluorescence assays were conducted similarly to the internalization assays except for using lower cell numbers and determining only the cellbound fraction. Briefly, A431-CCK2R, M21, and M21-L cells were diluted in corresponding media to a density of $2 \times 10^{6}$ cells/ $\mathrm{mL}$. Aliquots of $0.5 \mathrm{~mL}$ were transferred to Eppendorf tubessix technical replicates for A431-CCK2R unblocked and blocked and M21/M21-L, respectively-and treated in the same manner as described above. The nonradiolabeled particular ligand was added to a final concentration of $3 \mathrm{nM}$ and the tubes were kept in an incubator (Incubator hood TH15 and Compact shaker KS-15 control, Edmund Bühler GmbH, Hechingen, Germany) at $37{ }^{\circ} \mathrm{C}$ for $2 \mathrm{~h}$ under vigorously shaking $(420 / \mathrm{min})$. After centrifugation (2 min, $5000 \mathrm{rpm}$ ) washing steps were performed as mentioned before. Finally, each residual cell pellet was suspended in $200 \mu \mathrm{L}$ of phosphate buffered saline ( $\mathrm{pH} 7.35)$ and transferred carefully to a 96-well flat bottom white polystyrol plate (ThermoFischer ScientificNunclon). Fluorescence intensity was measured with Tecan Infinite 200 PRO series multiplate reader (Tecan Trading AG, Switzerland) by using Tecan Icontrol 1.1 software. Parameters were set as follows: Fluorescence Top reading; excitation/ emission wavelength $740 / 790 \mathrm{~nm}$; excitation bandwidth $9 \mathrm{~nm}$; emission bandwidth $20 \mathrm{~nm}$; gain optimal; number of flashes 25 ; integration time $25 \mu \mathrm{s}$. Results were calculated and expressed as percentage of cell-bound fluorescence in relation to the standards sample.

Whole Cell Receptor Binding Affinity $\left(I C_{50}\right)$ Studies. General. Receptor binding affinities were evaluated via a displacement cell-binding assay for metal free as well as metal bound $\left(\left[{ }^{\text {nat }} \mathrm{Ga}\right]\right)$ conjugates. Binding of nonradioactive gallium was performed in analogy to the radiolabeling procedure but instead of the generator eluate a 100-fold molar excess of gallium bromide $\left(\mathrm{GaBr}_{3}\right)$ dissolved in $100 \mu \mathrm{L} 0.1 \mathrm{~N} \mathrm{HCl}$ was used. Cells were prepared as described below and incubated with increasing concentrations $[0.001-1000 \mathrm{nM}]$ of competitor in triplicate. After addition of corresponding iodinated radioligand the 96-well MulitScreen Filter Plates HTS $(1 \mu \mathrm{m}$ glass fiber filter, Merck Millipore, Darmstadt, Germany) were incubated for 1 or $2 \mathrm{~h}$ at RT under shaking conditions (Compact shaker KS-15 control, 200/min) and after a washing step the remaining activity on the filter was measured in the $\gamma$ counter. The receptor affinity of DOTA-minigastrin 11 as well as $\mathrm{c}(\mathrm{RGDyV})$ were determined under the corresponding conditions as a reference. $\mathrm{IC}_{50}$ values were calculated by using nonlinear curve fitting with following formula NS+SB/ $\left(1+x / \mathrm{IC}_{50}\right)$ on Origin 6.1 software (Northampton, MA, USA). A detailed description regarding iodination can be found in the Supporting Information.

A431-CCK2R cells were diluted in $50 \mathrm{mM}$ HEPES buffer ( $\mathrm{pH} 7.3$ ) containing $5 \mathrm{mM} \mathrm{MgCl}_{2}$ and $0.3 \%$ BSA to a density of $5 \times 10^{6}$ cells $/ \mathrm{mL}$. 96-well plates were washed with $200 \mu \mathrm{L}$ of 10 $\mathrm{mM}$ TRIS buffered saline ( $\mathrm{pH} 7.3$ ) and $100 \mu \mathrm{L}$ of cell suspension were added to each well. Hereafter $50 \mu \mathrm{L}$ of competitor solution $\left\{\left(\left[{ }^{\text {nat }} \mathrm{Ga}\right]\right)\right.$ Sulfo-Cy7-FSC-MG or DOTAminigastrin ${ }^{11}$ diluted in $20 \mathrm{mM}$ HEPES; $10 \mathrm{mM} \mathrm{MgCl}_{2}$ and $0.1 \% \mathrm{BSA}$ \} of each concentration were added and left for 10 min at RT. After incubation with $50 \mu \mathrm{L}$ of radioligand (human $\left[{ }^{125} \mathrm{I}\right]$-[Leu $\left.{ }^{15}\right]$-Gastrin I $\left.4.5 \times 10^{4} \mathrm{cpm}\right)$ for $1 \mathrm{~h}$ the plate was washed twice with $200 \mu \mathrm{L}$ TRIS-buffer/well.

Integrin binding affinity assay was adapted from Yun Wu et al. ${ }^{31}$ Briefly, M21 cells were washed two times with phosphate buffered saline followed by suspension in binding buffer $(=20$ $\mathrm{mM}$ TRIS pH $7.4+150 \mathrm{mM} \mathrm{NaCl}+2 \mathrm{mM} \mathrm{CaCl}_{2}+1 \mathrm{mM}$ $\mathrm{MgCl}_{2}+1 \mathrm{mM} \mathrm{MnCl} 20.1 \%$ BSA). 96-well plates were washed with $200 \mu \mathrm{L}$ of $20 \mathrm{mM}$ TRIS-buffer and seeded with $1 \times 10^{6}$ 
cells/well $\left(10^{7}\right.$ cells $\left./ \mathrm{mL}\right)$. After $10 \mathrm{~min}$ of incubation in the presence of the competitor $\left\{\left(\left[{ }^{\text {nat }} \mathrm{Ga}\right]\right)\right.$ Sulfo-Cy7-FSC-RGD or $\mathrm{c}(\mathrm{RGDyV})$ diluted in binding buffer $)\}$ volume was adjusted to $200 \mu \mathrm{L} /$ well by adding $50 \mu \mathrm{L}$ of radioligand ([$\left.{ }^{125} \mathrm{I}\right]-\mathrm{c}(\mathrm{RGDyV})$, $\left.4.5 \times 10^{4} \mathrm{cpm}\right)$ and the plate was left for $2 \mathrm{~h}$ at RT. Finally the supernatant was removed by vacuum and each well was washed three times with $200 \mu \mathrm{L}$ ice-cold binding buffer.

Animal Experiments. General. All animal experiments were conducted in accordance with regulations and guidelines of the Czech Animal Protection Act (No. 246/1992), and with the approval of the Czech Ministry of Education, Youth, and Sports (MSMT-22421/2013-12), and the institutional Animal Welfare Committee of the Faculty of Medicine and Dentistry of Palacky University in Olomouc. The studies were performed using female 8-10-week-old athymic BALB/c nude mice (Envigo, Horst, The Netherlands). The number of animals was reduced as much as possible $(n=3$ per group and time point for all experiments) and retro-orbital (r.o.) tracer injection as well as small animal imaging was carried out under $2 \%$ isoflurane anesthesia (FORANE, Abbott Laboratories, Abbott Park, IL, USA) to minimize animal suffering.

Tumor Xenograft Preparation, Ex Vivo Biodistribution, and Small Animal Imaging Studies. Tumor xenografts were established near the front shoulder of mice by subcutaneous injection of $5 \times 10^{6}$ cells (U-87 MG) or $2 \times$ $10^{6}$ cells (A431-CCK2R) and the same amount of A431-mock cells as a control in $200 \mu \mathrm{L}$ appropriate medium and Matrigel (1:1). The tumors were allowed to grow until they had reached a volume of 0.2 to $0.5 \mathrm{~cm}^{3}$. To evaluate ex vivo biodistribution mice were injected with $1-2 \mathrm{MBq}(0.05-0.14 \mathrm{nmol})$ of radiotracer per mouse and mice were sacrificed by cervical dislocation after 30 and $90 \mathrm{~min}$ for $\left[{ }^{68} \mathrm{Ga}\right]$ Sulfo-Cy7-FSC-RGD and after 1 and $2 \mathrm{~h}$ in the case of $\left[{ }^{68} \mathrm{Ga}\right]$ Sulfo-Cy7-FSC-MG. Tumors, blood, muscle tissue, and organs were extracted, weighed, and activity uptake of the samples was measured in the gamma counter. Results were expressed as percentage of injected dose per gram tissue (\% ID/g). In vivo PET and CT images were acquired with an Albira PET/SPECT/CT small animal imaging system (Bruker Biospin Corporation, Woodbridge, CT, USA). Xenograft bearing mice were injected with radiolabeled peptides in a dose of $\sim 5 \mathrm{MBq}$ corresponding to $1-2 \mu \mathrm{g}(0.25-0.58 \mathrm{nmol})$ of peptide per mouse. Anaesthetized animals were positioned prone head first in the Albira system before the start of imaging. Static PET/CT imaging was carried out 30 and $90 \mathrm{~min}$ p.i. for $\left[{ }^{68} \mathrm{Ga}\right]$ Sulfo-Cy7-FSC-RGD. Animals injected with $\left[{ }^{68} \mathrm{Ga}\right]$ Sulfo-Cy7-FSC-MG were imaged 1 and $2 \mathrm{~h}$ p.i. A $10 \mathrm{~min}$ PET scan (axial FOV $148 \mathrm{~mm}$ ) was performed, followed by a CT scan (axial FOV $65 \mathrm{~mm}, 45 \mathrm{kVp}, 400 \mu \mathrm{A}$, at 400 projections). Scans were reconstructed with the Albira software (Bruker Biospin Corporation, Woodbridge, CT, USA) using the maximum likelihood expectation maximization (MLEM) and filtered backprojection (FBP) algorithms. After reconstruction, acquired data was viewed and analyzed with PMOD software (PMOD Technologies Ltd., Zurich, Switzerland). 3D images were obtained using VolView software (Kitware, Clifton Park, NY, USA). Near-infrared in vivo fluorescence imaging was performed with an In-Vivo MS FX PRO small animal imaging system (Bruker Biospin Corporation, Woodbridge, CT, USA). Sulfo-Cy7-FSC-MG and SulfoCy7-FSC-RGD were injected in a dose of $0.25-0.58 \mathrm{nmol}$ per mouse and after supine head first positioning, imaging was conducted in various time intervals up to $72 \mathrm{~h}$ p.i. An appropriate filter set (excitation $=730 \mathrm{~nm}$ and emission $=790$ $\mathrm{nm}$ ) was used for acquiring the Sulfo-Cy7-FSC-peptide fluorescence in vivo. Identical illumination settings (acquisition time $=15 \mathrm{~s}$, filters $=730 / 790 \mathrm{~nm}$, f-stop $=2.8$, field of view $=$ $100 \mathrm{~mm}$, and binning $=4 \times 4$ ) were used for acquiring all images, and fluorescence emission was normalized to photons/ $\mathrm{s} / \mathrm{mm}^{2}$. Images were acquired and analyzed using Bruker MI SE software (Bruker Biospin Corporation, Woodbridge, CT, USA).

\section{ASSOCIATED CONTENT}

\section{S Supporting Information}

The Supporting Information is available free of charge on the ACS Publications website at DOI: 10.1021/acs.bioconjchem.7b00182.

Experimental details on iodination of ligands used for displacement assay, detailed RP-HPLC chromatograms of all synthetical intermediates and final bioconjugates, analysis of ${ }^{68} \mathrm{Ga}$-labeled hybrid imaging agents (ITLC/ HPLC) and corresponding stability studies in human serum and PBS (HPLC) (PDF)

\section{AUTHOR INFORMATION}

\section{Corresponding Author}

*E-mail: Clemens.Decristoforo@i-med.ac.at; Tel: +4351250480951; Fax:+435125046780951.

ORCID $\odot$

Leo Grossrubatscher: 0000-0002-7705-4168

Clemens Decristoforo: 0000-0003-0566-4036

\section{Notes}

The authors declare no competing financial interest.

\section{ACKNOWLEDGMENTS}

The authors gratefully acknowledge the financial support of the Austrian Science Foundation (FWF) grants P 25899-B23 and I 1346, financial support from Ministry of Education, Youth and Sports of the Czech Republic (LO1304) and Technology Agency of the Czech Republic (TE01020028). Furthermore, we highly appreciate Heinz Zoller and Nadja Baumgartner, Department of Internal Medicine II, Innsbruck Medical University, for making MALDI-TOF analysis available. We address special thanks to Andreas Ritsch and Tamara Bernscherer, Department of Internal Medicine I, Innsbruck Medical University for their excellent technical assistance regarding fluorescence measurements on Tecan Infinite 200 PRO series.

\section{ABBREVIATIONS}

PET, positron emission tomography; CT, computed tomography; OI, optical imaging; FSC, fusarinine $\mathrm{C}$; $\mathrm{MG}$, minigastrin; CCK2R, cholecystokinin-2 receptor; RGD, integrin $\alpha_{\mathrm{V}} \beta_{3}$ targeting cyclic pentapeptide; p.i., post-injection; NHS, Nhydroxysuccinimide; RCY, radiochemical yield; RCP, radiochemical purity; SA, specific activity; MALDI-TOF MS, matrixassisted laser desorption/ionization time-of-flight mass spectrometry; RP-HPLC, reversed-phase high-performance liquid chromatography; ITLC, instant thin layer chromatography; DOTA, 1,4,7,10-tetraazacyclododecane-1,4,7,10-tetraacetic acid; DTPA, diethylene triamine pentoacetic acid; DFO, deferoxamine; PBS, phosphate buffered saline; TRIS, tris(hydroxymethyl)aminomethane; EDTA, ethylenediaminetetraacetic acid; \% ID/g, percentage injected dose per gram; $\mathrm{ACN}$, 
acetonitrile; TFA, trifluoroacetic acid; DMF, dimethylformamide; DIPEA, $\mathrm{N}, \mathrm{N}$-diisopropylamine; RT, room temperature; Fmoc, 9-fluorenylmethyl chloroformate

\section{REFERENCES}

(1) Mankoff, D. A., Link, J. M., Linden, H. M., Sundararajan, L., and Krohn, K. A. (2008) Tumor Receptor Imaging. J. Nucl. Med. 49, 149S-163S.

(2) Laverman, P., Sosabowski, J. K., Boerman, O. C., and Oyen, W. J. G. (2012) Radiolabelled peptides for oncological diagnosis. Eur. J. Nucl. Med. Mol. Imaging 39, S78-S92.

(3) Ambrosini, V., Fani, M., Fanti, S., Forrer, F., and Maecke, H. R. (2011) Radiopeptide Imaging and Therapy in Europe. J. Nucl. Med. 52, 42S-55S.

(4) Velikyan, I. (2014) Prospective of ${ }^{68} \mathrm{Ga}$-Radiopharmaceutical development. Theranostics 4, 47-80.

(5) van Leeuwen, F. W. B., de Jong, M., Evangelista, L., Barbet, J., del Vecchio, S., and Schibli, R. (2014) Molecular imaging: the emerging role of optical imaging in nuclear medicine. Eur. J. Nucl. Med. Mol. Imaging 41, 2150-2153.

(6) Owens, E. A., Henary, M., El Fakhri, G., and Choi, H. S. (2016) Tissue-Specific Near-Infrared Fluorescence Imaging. Acc. Chem. Res. 49, 1731-1740.

(7) Zhu, B., and Godavarty, A. (2016) Near-Infrared FluorescenceEnhanced Optical Tomography. BioMed Res. Int. 10, 1.

(8) Lütje, S., Rijpkema, M., Helfrich, W., Oyen, W. J. G., and Boerman, O. C. (2014) Targeted Radionuclide and Fluorescence Dual-modality Imaging of Cancer: Preclinical Advances and Clinical Translation. Mol. Imaging Biol. 16, 747-755.

(9) Zhang, H., Desai, P., Koike, Y., Houghton, J., Carlin, S. D., Tandon, N., Touijer, K., and Weber, W. A. (2017) Dual modality imaging of prostate cancer with a fluorescent and radiogallium-labeled GRP receptor antagonist. J. Nucl. Med. 58, 29-35.

(10) Louie, A. (2010) Multimodality imaging probes: Design and challenges. Chem. Rev. 110, 3146-3195.

(11) Ha, Y., and Choi, H. K. (2016) Recent conjugation strategies of small organic fluorophores and ligands for cancer-specific bioimaging. Chem.-Biol. Interact. 248, 36-51.

(12) Sun, Y., Ma, X., Cheng, K., Wu, B., Duan, J., Chen, H., Bu, L., Zhang, R., Hu, X., Deng, Z., Xing, L., and Hong, X. (2015) Strained cyclooctyne as a molecular platform for construction of multimodal imaging probes. Angew. Chem., Int. Ed. 54, 5981-5984.

(13) Carlucci, G., Ananias, H. J. K., Yu, Z., Van de Wiele, C., Dierckx, R. A., de Jong, I. J., and Elsinga, P. H. (2012) Multimerization improves targeting of peptide radio-pharmaceuticals. Curr. Pharm. Des. $18,2501-2516$.

(14) Knetsch, P. A., Zhai, C., Rangger, C., Blatzer, M., Haas, H., Kaeopookum, P., Haubner, R., and Decristoforo, C. $(2015)\left[{ }^{68} \mathrm{Ga}\right]-$ FSC-(RGD $)_{3}$ a trimeric RGD peptide for imaging $\alpha_{v} \beta_{3}$ integrin expression based on a novel siderophore derived chelating scaffoldsynthesis and evaluation. Nucl. Med. Biol. 42, 115-122.

(15) Zhai, C., Summer, D., Rangger, C., Franssen, G. M., Laverman, P., Haas, H., Petrik, M., Haubner, R., and Decristoforo, C. (2015) Novel Bifunctional Cyclic Chelator for ${ }^{89} \mathrm{Zr}$ Labeling-Radiolabeling and Targeting Properties of RGD Conjugates. Mol. Pharmaceutics 12, 2142-50.

(16) Dufresne, M., Seva, C., and Fourmy, D. (2006) Cholecystokinin and gastrin receptors. Physiol. Rev. 86, 805-847.

(17) Haubner, R., Wester, H. J., Reuning, U., SenekowitschSchmidtke, R., Diefenbach, B., Kessler, H., Stöcklin, G., and Schwaiger, M. (1999) Radiolabeled $\alpha_{v} \beta_{3}$ integrin antagonists: A new class of tracers for tumor targeting. J. Nucl. Med. 40, 1061-1071.

(18) Haubner, R., Gratias, R., Diefenbach, B., Goodman, S. L., Jonczyk, A., and Kessler, H. (1996) Structural and functional aspects of RGD-containing cyclic pentapeptides as highly potent and selective integrin $\alpha_{\mathrm{v}} \beta_{3}$ antagonists. J. Am. Chem. Soc. 118, 7461-7472.

(19) Gibbs, S. L. (2012) Near infrared fluorescence for image-guided surgery. Quant. Imaging Med. Surg. 2, 177-87.
(20) Frangioni, J. V. (2003) In vivo near-infrared fluorescence imaging. Curr. Opin. Chem. Biol. 7, 626-634.

(21) Li, C., Wang, W., Wu, Q., Ke, S., Houston, J., Sevick-Muraca, E., Dong, L., Chow, D., Charnsangavej, C., and Gelovani, J. G. (2006) Dual optical and nuclear imaging in human melanoma xenografts using a single targeted imaging probe. Nucl. Med. Biol. 33, 349-358.

(22) Ye, Y., Bloch, S., Xu, B., and Achilefu, S. (2008) A Novel NearInfrared Fluorescent Integrin Targeted DFO Analog. Bioconjugate Chem. 19, 225-234.

(23) Edwards, W. B., Akers, W. J., Ye, Y., Cheney, P. P., Bloch, S., Laforesta, R., and Achilefu, S. (2009) Multimodal Imaging of Integrin Receptor-Positive Tumors by Bioluminescence, Fluorescence, Gamma Scintigraphy and SPECT Methods Using a Cyclic RGD Peptide Labeled with a Near Infrared Fluorescent Dye and a Radionuclide. Mol. Imaging 8, 101-110.

(24) Kang, C. M., Koo, H.-J., An, G. I., Choe, Y. S., Choi, J. Y., Lee, K.-H., and Kim, B.-T. (2015) Hybrid PET/optical imaging of integrin $\alpha \mathrm{V} \beta 3$ receptor expression using a ${ }^{64} \mathrm{Cu}$-labeled streptavidin/biotinbased dimeric RGD peptide. EJNMMI Res.10.1186/s13550-015-01400

(25) Breeman, W. A. P., Fröberg, A. C., de Blois, E., van Gameren, A., Melis, M., de Jong, M., Maina, T., Nock, B. A., Erion, J. L., and Mäcke, H. R. (2008) Optimised labeling, preclinical and initial clinical aspects of CCK-2 receptor-targeting with 3 radiolabeled peptides. Nucl. Med. Biol. 35, 839-849.

(26) Dijkgraaf, I., Yim, C.-B., Franssen, G. M., Schuit, R. C., Luurtsema, G., Liu, S., Oyen, W. J. G., and Boerman, O. C. (2011) PET imaging of $\alpha_{\mathrm{v}} \beta_{3}$ integrin expression in tumours with ${ }^{68} \mathrm{Ga}$-labelled mono-, di- and tetrameric RGD peptides. Eur. J. Nucl. Med. Mol. Imaging 38, 128-137.

(27) Rauf, M. A., and Ashraf, S. S. (2009) Radiation induced degradation of dyes-An overview. J. Hazard. Mater. 166, 6-16.

(28) Hernandez, R., Heskamp, S., Rijpkema, M., Bos, D. L., Goldenberg, D. M., McBride, W. J., Morgenstern, A., Bruchertseifer, F., Cai, W., and Boerman, O. C. (2017) Preventing Radiobleaching of Cyanine Fluorophores Enhances Stability of Nuclear/NIRF Multimodality Imaging Agents. Theranostics 7, 1-8.

(29) Kossatz, S., Mansi, R., Béhé, M., Czerney, P., and Hilger, I. (2013) Influence of d-glutamine and d-glutamic acid sequences in optical peptide probes targeted against the cholecystokinin-2/gastrinreceptor on binding affinity, specificity and pharmacokinetic properties. EJNMMI Res. 3, 75.

(30) Zhai, C., Franssen, G. M., Petrik, M., Laverman, P., Summer, D., Rangger, C., Haubner, R., Haas, H., and Decristoforo, C. (2016) Comparison of Ga-68-Labeled Fusarinine C-Based Multivalent RGD Conjugates and [68Ga]NODAGA-RGD-In Vivo Imaging Studies in Human Xenograft Tumors. Mol. Imaging Biol. 18, 758-767.

(31) Wu, Y., Cai, W., and Chen, X. (2006) Near-infrared fluorescence imaging of tumor integrin $\alpha_{\mathrm{v}} \beta_{3}$ expression with Cy7-labeled RGD multimers. Mol. Imaging Biol. 8, 226-236.

(32) Shi, J., Kim, Y.-S., Zhai, S., Liu, Z., Chen, X., and Liu, S. (2009) Bioconjugate Chem. 20, 750-759.

(33) Kossatz, S., Béhé, M., Mansi, R., Saur, D., Czerney, P., Kaiser, W. A., and Hilger, I. (2013) Multifactorial diagnostic NIR imaging of CCK2R expressing tumors. Biomaterials 34, 5172-5180.

(34) Shi, J., Kim, Y.-S., Chakraborty, S., Jia, B., and Wang, F. (2009) 2-Mercaptoacetylglycylglycyl $\left(\mathrm{MAG}_{2}\right)$ as a Bifunctional Chelator for ${ }^{99 \mathrm{~m}}$ Tc-Labeling of Cyclic RGD Dimers: Effect of Technetium Chelate on Tumor Uptake and Pharmacokinetics. Bioconjugate Chem. 20, $1559-1568$

(35) Notni, J., Pohle, K., and Wester, H. J. (2013) Be spoilt for choice with radiolabelled RGD peptides: Preclinical evaluation of ${ }^{68} \mathrm{Ga}$ TRAP(RGD) ${ }_{3}$. Nucl. Med. Biol. 40, 33-41.

(36) Liu, L., Lin, G., Yin, F., Law, W.-C., and Yong, K.-T. (2016) Near-infrared fluorescent peptide probes for imaging of tumor in vivo and their biotoxicity evaluation. J. Biomed. Mater. Res., Part A 104A, 910-916.

(37) Brechbiel, M. W. (2008) Bifunctional chelates for metal nuclides. Q. J. Nucl. Med. Mol. Imaging 52, 166-173. 
(38) Pfister, J., Summer, D., Rangger, C., Petrik, M., von Guggenberg, E., Minazzi, P., Giovenzana, G. B., Aloj, L., and Decristoforo, C. (2015) Influence of a novel, versatile bifunctional chelator on theranostic properties of a minigastrin analogue. EJNMMI Res. 10.1186/s13550-015-0154-7

(39) Haubner, R., Kuhnast, B., Mang, C., Weber, W. a., Kessler, H., Wester, H.-J., and Schwaiger, M. (2004) $\left[{ }^{18} \mathrm{~F}\right]$ Galacto-RGD: Synthesis, Radiolabeling, Metabolic Stability, and Radiation Dose Estimates. Bioconjugate Chem. 15, 61-69.

(40) Schrettl, M., Bignell, E., Kragl, C., Sabiha, Y., Loss, O., Eisendle, M., Wallner, A., Arst, H. N., Haynes, K., and Haas, H. (2007) Distinct roles for intra- and extracellular siderophores during Aspergillus fumigatus infection. PLoS Pathog. 3, e128.

(41) Aloj, L., Caracò, C., Panico, M., Zannetti, A., Del Vecchio, S., Tesauro, D., De Luca, S., Arra, C., Pedone, C., Morelli, G., and Salvatore, M. (2004) In vitro and in vivo evaluation of ${ }^{111} \mathrm{In}$ DTPAGlu-G-CCK8 for cholecystokinin-b receptor imaging. J. Nucl. Med. 45, 485-494. 